\title{
(2) OPEN ACCESS \\ Costs of vaping: evidence from ITC Four Country Smoking and Vaping Survey
}

\author{
Kai-Wen Cheng (0) , ${ }^{1,2}$ Ce Shang, ${ }^{3}$ Hye Myung Lee, ${ }^{2}$ Frank J Chaloupka, ${ }^{2}$ \\ Geoffrey T Fong (ㄷ), ${ }^{4,5}$ Ron Borland (ㄷ), 6,7 Bryan W Heckman (1) , 8,9 \\ Sara C Hitchman \& ${ }^{\prime}{ }^{10}$ Richard J O'Connor, ${ }_{1}^{11}$ David T Levy (1) , ${ }^{12}$ \\ K. Michael Cummings (1) 8,9
}

- Additional material is published online only. To view please visit the journal online (http://dx.doi.org/10.1136/ tobaccocontrol-2019-055344)

For numbered affiliations see end of article.

\section{Correspondence to} Dr Kai-Wen Cheng, Department of Health Administration, Governors State University, University Park, IL 60466, USA; kcheng@govst.edu

Received 21 August 2019 Revised 12 November 2019 Accepted 19 November 2019 Published Online First 21 February 2020

\section{ABSTRACT}

Study objectives To compare the prices paid for nicotine vaping products (NVPs) and supplies among current NVP users to prices paid for cigarettes among current smokers.

Data The 2016 International Tobacco Control Four Country Vaping and Smoking Survey (4CV1). Key measures included: (1) self-reported prices paid for reusable NVPs (eg, rechargeable devices with cartridges and tank system devices with e-liquids) in the 3-month period prior to the survey among current NVP users, (2) prices paid for disposable NVPs, cartridges and e-liquids purchased in the last 30 days among current NVP users and (3) self-reported prices paid for cigarettes among current smokers.

Results Disposable NVP price was higher than the price of a comparable unit for combustible cigarettes in England (EN), USA and Canada (CA). Prefilled cartridge price was higher than the price of a comparable unit of cigarettes in USA and CA, but lower in EN and Australia. E-liquid price was consistently lower than the price of a comparable unit of cigarettes across four countries. For start-up costs, price of a rechargeable device is approximately $3-5$ times higher than a pack of cigarettes in four countries.

Conclusion NVP prices were generally higher than prices of combustible cigarettes, especially the high upfront NVP devices. The high upfront costs of purchasing a reusable NVP may discourage some smokers from switching to vaping. However, the average lower costs of cartridges and e-liquids relative to a package of cigarettes make switching to a NVP an attractive alternative to smoking in the long term so long as smokers switch completely to vaping.

\section{INTRODUCTION}

While cigarettes are the most frequently used nicotine product among adults around the world, use of non-cigarette nicotine products and multiple products is growing in popularity. ${ }^{1}$ Among the noncigarette nicotine products, nicotine vaping products (NVPs), a vaping device or vaporiser delivering nicotine in vapour or aerosol form, have gained substantial global market share. In 2017, North America was the largest NVP product market in the world, followed by Western Europe, led by the UK, Eastern Europe, Asia Pacific and then the rest of the world. ${ }^{2}$ In 2018, global sales of NVP reached US $\$ 13$ billion and are expected to continue their rapid growth over the coming years. ${ }^{2}$ An estimated
35 million people were NVP users in 2016, a number projected to grow to 55 million by $2021 .^{2}$

Several factors may be driving the growing popularity of NVPs. Among them, the relatively lower cost of vaping compared with smoking is thought to be a key factor. Recent evidence suggests that NVP use and sales are price-sensitive, such that an increase of NVP price is associated with a decrease in NVP sales and use prevalence..$^{3-7}$ In addition to being sensitive to its own price, NVP sales and use are sensitive to the prices of other nicotine products. A change in relative prices among nicotine products, such as cigarettes, cigars, NVPs (disposable, open system device, closed system device) may lead users to switch to using the alternatives with lower prices. ${ }^{3-5}$

The relative price of NVPs compared with cigarettes is likely an important factor in driving growth of NVPs. However, limited empirical work has measured and described the prices of NVP products compared with cigarettes in different markets. A review of global data found that NVP users' impressions of cost were inconsistent such that some thought NVPs saved money while others believed that NVPs cost more money. ${ }^{8}$ Jackson et a $l^{9}$ used England household survey and found the expenditure on nicotine products among NVP users is approximately one third of the expenditure among cigarette smokers. ${ }^{9}$

Liber et al (2017) used data from multiple countries and comparing prices of NVPs with respect to combustible cigarettes. They found that global NVP prices are generally much higher than those of cigarettes, while e-liquids $(\mathrm{mL})$ cost less, particularly in high-income countries.

For the US study, most of the data on cigarette and NVP prices comes from Nielsen Scanner Track where studies show the trends in NVP prices have decreased between 2012 and 2016 and the price gaps for NVP devices and cigarettes has narrowed. ${ }^{3} 1011$

Liber et al (2017) used Euromonitor International data which provides only a selected sample of NVP product prices, and it is uncertain whether their prices for disposable NVPs and e-liquids can be representative of all product prices in each country. ${ }^{12}$ Nielsen Scanner Track data have the sales information from participating retailers, which only reflects about $1 / 3$ or less of the NVP purchases. ${ }^{13}$

Our study extends previous studies reporting on the price of NVPs by using the self-reported prices of NVPs and cigarettes from NVP users and smokers in the four countries (Australia (AU), 
Table 1 Average price of cigarettes and nicotine vaping products without outliers, $95 \% \mathrm{Cl}$ in brackets, dollar amount in local currency

\begin{tabular}{|c|c|c|c|c|c|c|}
\hline & \multirow[b]{2}{*}{$\begin{array}{l}\text { Cigarette } \\
\text { (per stick) }\end{array}$} & \multirow[b]{2}{*}{$\begin{array}{l}\text { Disposable } \\
\text { (per stick) }\end{array}$} & \multicolumn{2}{|l|}{ E-liquid } & \multicolumn{2}{|l|}{ Cartridge } \\
\hline & & & $\begin{array}{l}\text { E-liquid } \\
\text { (per ml) }\end{array}$ & $\begin{array}{l}\text { Rechargeable } \\
\text { (per device) }\end{array}$ & $\begin{array}{l}\text { Cartridge } \\
\text { (per } \mathrm{mL} \text { ) }\end{array}$ & $\begin{array}{l}\text { Rechargeable } \\
\text { (per device) }\end{array}$ \\
\hline Australia & $\$ 0.91$ (0.89 to 0.93$)$ & $\$ 9.90$ (4.21 to 15.59$)$ & $\$ 0.47(0.44$ to 0.50$)$ & $\$ 85.61$ (79.36 to 91.85$)$ & $\$ 2.23(0.31$ to 4.15$)$ & $\$ 57.59$ (41.71 to 73.48 ) \\
\hline Canada & $\$ 0.49(0.48$ to 0.50$)$ & $\$ 11.84$ (9.09 to 14.60$)$ & $\$ 0.85$ (0.71 to 0.98$)$ & $\$ 58.20$ (52.84 to 63.57$)$ & $\$ 3.84$ (3.17 to 4.51$)$ & $\$ 38.16$ (33.64 to 42.68$)$ \\
\hline England & $£ 0.41$ (0.40 to 0.42$)$ & f8.93 (6.68 to 11.17$)$ & f0.34 (0.32 to 0.37$)$ & f25.10 (23.16 to 27.04$)$ & f1.67 (1.42 to 1.92$)$ & f16.86 (15.28 to 18.44$)$ \\
\hline USA & $\$ 0.39(0.37$ to 0.41$)$ & $\$ 14.85$ (11.06 to 18.63$)$ & $\$ 0.91(0.75$ to 1.04$)$ & $\$ 44.81$ (39.73 to 49.60$)$ & $\$ 3.49$ (2.94 to 4.03$)$ & $\$ 34.16$ (29.62 to 38.69$)$ \\
\hline
\end{tabular}

Canada (CA), England (EN) and the USA), which represents a majority of global NVP sale. Using self-reported prices allows us collect prices of NVPs obtained from different purchase locations (eg, retailers, vape shops and online). Our study aims to (1) assess the unit comparable prices of NVPs, by standardising the self-reported nicotine content/volume in different types of NVPs and (2) assess the upfront cost of rechargeable NVP device.

\section{METHODS}

\section{Data}

Data were obtained from the international tobacco control (ITC) Four Country Smoking and Vaping Survey Wave 1 (2016) (ITC 4CV1). Details about this survey can be found in Thompson et al (2019). ${ }^{14}$

The ITC 4CV1 Survey provided information on self-reported prices of reusable vaping devices (eg, rechargeable devices with cartridges and tank system devices with e-liquids) among the ever NVP users who purchased a vaping device in the past 3 months. The survey also provided information on self-reported prices of disposable NVPs, cartridges and e-liquids among the ever NVP users who had purchased any disposable, cartridges and/or e-liquid in the last 30 days. Current smokers who reported using factorymade cigarettes provided their cigarette price information.

After removing outliers ( \pm 2 SD from the mean; $n=152(2 \%)$ for the removed price outliers and $n=53(4 \%)$ for the removed NVP device price outliers), our final sample size is 9125 for cigarette price, disposable price, e-liquid price, cartridge price and 1200 for rechargeable device with cartridges and tank system device with e-liquids for AU, CA, EN and USA (online supplementary tables A-1 and A-2).

\section{Measures}

Cigarette prices per stick

Current smokers who smoked and purchased combustible and factory-made cigarettes were asked in which form they purchased cigarettes: by the stick, pack, carton or bag. Based on these purchase forms as well as the reported number of cigarettes per pack, carton or bag, price per stick was calculated. A small number of respondents $(\mathrm{AU}=4, \mathrm{CA}=6, \mathrm{EN}=14, \mathrm{USA}=15)$ reported that they purchased factory-made cigarette loose out of packs. For those who purchased loose cigarettes, cigarette prices were divided by the number of cigarettes purchased.

\section{NVP prices}

Current NVP users who purchased a reusable vaping device (eg, replaceable prefilled cartridges and tank system filled with liquids) in the last 3 months were asked to report the price for the rechargeable device (rechargeables with cartridges and tank systems with e-liquids).

NVP users who used prefilled cartridges most/last and answered that they had made a purchase in the last 30 days were asked to report price per cartridge. NVP users who answered that they used tanks filled with liquid most/last were asked to report price per bottle of e-liquid. Those who used disposables most/last were asked to report the price per disposable NVP.

\section{Capacity of e-liquid bottles and prefilled cartridges}

For e-liquid bottles and prefilled cartridges, capacity/volume was reported in millilitres (continuous variable) by users. Price per bottle (or cartridge) was divided by the capacity/volume (ml) of each bottle (or cartridge) in order to obtain the price per $\mathrm{mL}$ of e-liquid (or cartridge).

\section{Comparable price measures}

We used the unit-standardised approaches suggested by Liber et al (2017) to standardise NVP prices to a comparable unit, with prices per pack of 20 cigarettes as an anchor. A single stick of disposable NVP is a comparable unit for a pack of cigarettes, as previous studies identified that a single stick of disposable NVP produced a comparable number of puffs to a pack of combustible cigarettes (150 puffs). ${ }^{1516}$ For e-liquids, $3.55 \mathrm{~mL}$ is a comparable unit for a pack of cigarettes, as its consumption time was equal to the time in which typical pack-per-day smokers consume their normal daily ratio of cigarettes. ${ }^{17} 18$ Using similar logic to calculate a comparable unit for cartridges, the cartridge's volume/ capacity is taken into account and a cartridge with $3.55 \mathrm{~mL}$ is considered equivalent to a pack of 20 cigarettes.

\section{Price ratio}

Using this comparable unit standard, such that one pack of cigarettes was considered to represent the equivalent level of consumption as one disposable, $3.55 \mathrm{~mL}$ of e-liquid or $3.55 \mathrm{~mL}$ of cartridge, ${ }^{19}$ three types of price ratios were generated with standardised cigarette price as the base: price ratios of disposables to cigarettes, e-liquids to cigarettes and cartridges to cigarettes.

\section{RESULTS}

\section{Prices for rechargeable devices}

The average prices of e-liquid rechargeable device were AUD 85.61 (US\$63.65), CAD 58.20 (US\$43.92), £25.10 (US\$33.87) and US\$44.81, in AU, CA, EN and the USA, respectively. The average prices of rechargeable devices for cartridges were AUD 57.59 (US\$42.81), CAD 38.16 (US\$28.80), £ 16.86 (US\$22.75) and US\$34.16, in AU, CA, EN and the USA, respectively. The 2016 currency exchange rate from OECD exchange rate database was used to obtain device prices in US\$ (table 1).

\section{Price ratio: comparable prices for disposables, e-liquids and cartridges}

In $\mathrm{AU}$, price ratios were 0.54 for disposables, 0.09 for e-liquid and 0.43 for cartridges. Interestingly, cigarettes were more expensive than any NVP products in AU. In CA, the ratios were 1.21, 0.31 and 1.39 , respectively. In EN, they were $1.09,0.15$ and 0.72 , 
Table 2 Average price per comparable unit of cigarettes and nicotine vaping products, dollar amount in local currency

\begin{tabular}{lllll}
\hline & Cigarette (per pack) & Disposable (per stick) & E-liquid (for 3.55 mL) & Cartridge (for 3.55 mL) \\
\hline Australia & $\$ 18.20(17.80-18.60)$ & $\$ 9.90(4.21-15.59)$ & $\$ 1.67(1.56-1.78)$ & $\$ 7.92(1.10-14.73)$ \\
Canada & $\$ 9.80(9.60-10.00)$ & $\$ 11.84(9.09-14.60)$ & $\$ 3.02(2.52-3.48)$ & $\$ 13.63(11.25-16.01)$ \\
England & $£ 8.20(8.00-8.40)$ & $£ 8.93(6.68-11.17)$ & $\mathrm{f} .21(1.14-1.31)$ & $\mathrm{f5} .93(5.04-6.82)$ \\
USA & $\$ 7.80(7.40-8.20)$ & $\$ 14.85(11.06-18.63)$ & $\$ 3.23(2.66-3.69)$ & $\$ 12.39(10.44-14.31)$ \\
\hline
\end{tabular}

respectively. CA and EN showed similar relative prices, except cartridges were more expensive than cigarettes in CA, while in EN cartridges were cheaper than cigarettes. In the USA, price ratios were 1.90, 0.41 and 1.59, respectively. Generally, USA had the highest relative prices for disposable NVPs and cartridges among the four countries, with disposable NVPs nearly twice as expensive as conventional cigarettes (table 2 and figure 1).

\section{DISCUSSION}

This study provides the first evidence using self-reported prices paid for NVP devices and supplies compared with cigarettes in four countries. In general, we found price of disposable NVPs to be higher than the price of a comparable unit for combustible cigarettes in EN, USA and CA. Price of prefilled cartridges is higher than the price of a comparable unit of combustible cigarettes in USA and CA. By contrast, price of e-liquid is lower than the price of a comparable unit of combustible in all four countries. In AU, price of all NVP types is consistently lower than the price of a comparable unit of combustible, in part due to the very high cigarette prices there.

For startup costs, the cost of purchasing a rechargeable NVP with refilled cartridges or e-liquids is approximately 3-5 times higher than purchasing a pack of cigarettes across all four countries. For an average daily smoker who smokes around 15 cigarettes per day (CPD), it takes the equivalent of around 7 packs of 20 cigarettes to pay for the device, meaning the cost of purchasing a rechargeable device could be recovered in approximately 9-10 days.

In addition, our data indicate that while the startup price of using rechargeable NVPs is relatively high, once the starter kit is purchased, the additional cost for prefilled cartridges or bottles of e-liquids may be a financially attractive alternative to factorymade cigarettes, especially for smokers from AU and EN. The high upfront costs of purchasing a reusable NVP may discourage some smokers from switching to vaping. However, the average lower costs of cartridges and e-liquids relative to a package of cigarettes

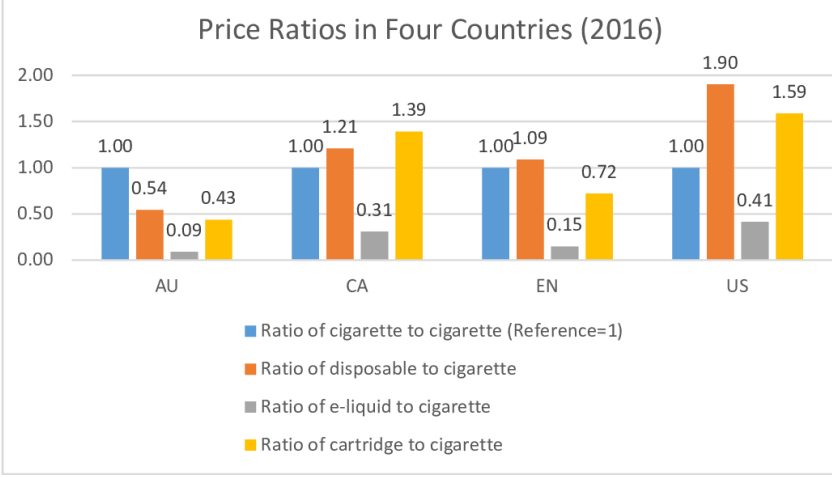

Figure 1 Price ratios using cigarette price as the base: price ratios of cigarettes to cigarettes, disposables to cigarettes, e-liquids to cigarettes and cartridges to cigarettes in $\mathrm{AU}, \mathrm{CA}, \mathrm{EN}$, and USA, respectively. makes switching to a NVP an attractive alternative to smoking in the long term so long as smokers switch completely to vaping.

The findings from this study underscores the importance of policy makers considering how policies they implement might impacting the relative price differential between NVPs and cigarettes. For example, policies that restrict where NVPs are sold could inadvertently increase the cost of NVPs relative to cigarettes making NVPs less attractive as cigarette substitutes. Regulators should consider tax systems for NVPs which imposes taxes high enough to discourage initiation among young people, but also keep the prices of NVPs low relative to the costs of cigarettes which pose a greater risk to health. ${ }^{20}$

This study does have several limitations that needed to be considered when interpreting the findings. First, our price data came from the single year of 2016. Some of the price data reported in this study when broken down by country and type of product purchased are based on relatively small samples of users which may yield unreliable price estimates. Second, this study only examined factory-made cigarette prices and does not take into account that many smokers report being able to obtain cigarettes at cheap prices, such as through the use of (roll your own) RYO. ${ }^{21}$ Thus, the price benefits from switching to NVPs for RYO smokers are likely less than for smokers of factory-made cigarettes. Third, NVP prices were standardised to a comparable and equivalent unit for nicotine volume, but the standardised nicotine unit does not imply that the delivered nicotine level is equivalent or that the nicotine salts are relevant across products. Future studies may benefit from complementing NVP prices from multiple data sources and using larger-scale and longitudinal data to explore the impact of relative prices on changes in use patterns between cigarettes and NVPs.

\section{What this paper adds}

What is already known on this subject

- Use of non-cigarette nicotine products and multiple products are growing in popularity around the world.

- Nicotine vaping product (NVP) use and sales are sensitive to its own price and also the prices of other nicotine products.

What important gaps in knowledge exist on this topic

- Limited empirical work has measured and described the prices of NVP products compared with cigarettes in different markets.

What this paper adds

- NVP prices were generally higher than prices of combustible cigarettes, especially the high upfront NVP devices that may discourage some smokers from switching to vaping.

- However, the average lower costs of cartridges and eliquids relative to a package of cigarettes makes completely switching to a NVP an attractive alternative to smoking in the long term. 


\section{CONCLUSION}

NVP prices were generally higher than prices of combustible cigarettes, especially the high upfront NVP devices, which may create for current smokers a barrier to switching to NVPs. However, the average lower costs of e-liquids relative to a package of cigarettes makes switching to a NVP an attractive alternative to smoking in the long term so long as smokers switch completely to vaping. Our study is relevant for policymakers who are considering policies that could impact the cost of NVPs such as excise taxes. We suggest that, while taxes should be set high enough to discourage the initiation of any nicotine products among nonusers, the tax rates applied on combustible and NVPs should be differentiated, creating a price advantage for NVPs relative to combustible cigarettes.

\section{Author affiliations}

'Department of Health Administration, Governors State University, University Park, Illinois, USA

${ }^{2}$ Health Policy Center, Institute for Health Research and Policy, University of Illinois at Chicago, Chicago, Illinois, USA

${ }^{3}$ Department of Pediatrics and Oklahoma Tobacco Research Center, University of Oklahoma Stephenson Cancer Center, Oklahoma City, Oklahoma, USA

${ }^{4}$ Department of Psychology and School of Public Health and Health Systems, University of Waterloo, Waterloo, Ontario, Canada

${ }^{5}$ Ontario Institute for Cancer Research, Toronto, Ontario, Canada

${ }^{6}$ School of Psychological Sciences, University of Melbourne, Melbourne, Victoria, Australia

${ }^{7}$ Cancer Council Victoria, Melbourne, Victoria, Australia

${ }^{8}$ Psychiatry and Behavioral Sciences, Medical University of South Carolina,

Charleston, South Carolina, USA

${ }^{9}$ Hollings Cancer Center, Medical University of South Carolina, Charleston, South Carolina, United States

${ }^{10}$ Department of Addictions, Institute of Psychiatry, Psychology \& Neuroscience, King's College London, London, UK

${ }^{11}$ Department of Health Behavior, Roswell Park Cancer Institute, Buffalo, New York, USA

${ }^{12}$ Department of Oncology, Lombardi Comprehensive Cancer Center, Georgetown University, Washington, District of Columbia, USA

Contributors K-WC wrote the original manuscript, conducted the empirical analysis and revised the manuscript. CS provided valuable insight on the analysis. HML managed the data and conducted statistical run. The other authors all took an active role in developing the original ideas for the study, critiquing the analysis and revising the manuscript.

Funding The ITC Four Country Smoking and Vaping Wave 2 Survey was supported by grants from the US National Cancer Institute (P01 CA200512) and the Canadian Institutes of Health Research (FDN-148477). The ITC Australia Project was supported by National Health and Medical Research Council of Australia (APP1106451). Additional support was provided to BWH by National Institute on Drug Abuse (NIDA) of the National Institutes of Health (K23 DA041616) and to GTF from a Senior Investigator Award from the Ontario Institute for Cancer Research.

Competing interests KMC has received grant funding from Pfizer, Inc. to study the impact of a hospital-based tobacco cessation intervention. KMC also receives funding as an expert witness in litigation filed against the tobacco industry. GTF has served as an expert witness on behalf of governments in litigation involving the tobacco industry.

\section{Patient consent for publication Not required.}

Ethics approval The survey protocols and all materials, including the survey questionnaires, were cleared for ethics by Institutional Review Board, Medical University of South Carolina; Research Ethics Office, King's College London, UK; Office of Research Ethics, University of Waterloo, Canada and Human Research Ethics, Cancer Council Victoria, Australia.

Provenance and peer review Not commissioned; externally peer reviewed.
Data availability statement Data are available on reasonable request. The data are public. The authors will make these data available to all who request it.

Open access This is an open access article distributed in accordance with the Creative Commons Attribution Non Commercial (CC BY-NC 4.0) license, which permits others to distribute, remix, adapt, build upon this work non-commercially, and license their derivative works on different terms, provided the original work is properly cited, appropriate credit is given, any changes made indicated, and the use is non-commercial. See: http://creativecommons.org/licenses/by-nc/4.0/.

\section{ORCID iDs}

Kai-Wen Cheng http://orcid.org/0000-0002-5508-2280

Geoffrey T Fong http://orcid.org/0000-0001-9098-6472

Ron Borland http://orcid.org/0000-0003-0059-178X

Bryan W Heckman http://orcid.org/0000-0003-4148-2467

Sara C Hitchman http://orcid.org/0000-0001-6155-6916

David T Levy http://orcid.org/0000-0001-5280-3612

K. Michael Cummings http://orcid.org/0000-0002-7103-7017

\section{REFERENCES}

1 The Foundation for Smoke-free World. Global trends in nicotine, 2018.

2 Euromonitor International. Global tobacco: key findings Part II: vapour products, 2017

3 Huang J, Tauras J, Chaloupka FJ. The impact of price and tobacco control policies on the demand for electronic nicotine delivery systems. Tob Control 2014;23:iii41-7.

4 Huang J, Duan Z, Kwok J, et al. Vaping versus JUULing: how the extraordinary growth and marketing of JUUL transformed the US retail e-cigarette market. Tob Control 2019;28:146-51

5 Zheng Y, Zhen C, Dench D, et al. U.S. demand for tobacco products in a system framework. Health Econ 2017;26:1067-86.

6 Cheng K-W, Chaloupka FJ, Shang C, et al. Prices, use restrictions and electronic cigarette use-evidence from wave 1 (2016) US data of the ITC four country smoking and Vaping survey.. Addiction 2019;114:115-22.

7 Heckman BW, Fong GT, Borland R, et al. The impact of vaping and regulatory environment on cigarette demand: behavioral economic perspective across four countries. Addiction 2019:114:123-33.

8 Pepper JK, Brewer NT. Electronic nicotine delivery system (electronic cigarette) awareness, use, reactions and beliefs: a systematic review. Tob Control 2014;23:375-84

9 Jackson SE, Shahab L, Kock L, et al. Expenditure on smoking and alternative nicotine delivery products: a population survey in England. Addiction 2019;114:2026-36.

10 Wang JB, Olgin JE, Nah G, et al. Cigarette and e-cigarette dual use and risk of cardiopulmonary symptoms in the health eHeart study. PLoS One 2018;13:e0198681.

11 Loomis BR, Rogers T, King BA, et al. National and state-specific sales and prices for electronic Cigarettes-U.S., 2012-2013. Am J Prev Med 2016;50:18-29.

12 Braak D, Cummings K, Nahhas G, et al. Where do vapers buy their vaping supplies? findings from the International tobacco control (ITC) 4 country smoking and Vaping survey. Int J Environ Res Public Health 2019;16:338.

13 Cummings KM BD, Nahhas GJ. How does the regulatory environment influence where vapers get their products: findings from the International tobacco control (ITC) project.. In Press 2018.

14 Thompson ME, Fong GT, Boudreau C, et al. Methods of the ITC four country smoking and Vaping survey, wave 1 (2016). Addiction 2019;114:6-14.

15 Pagano T, DiFrancesco AG, Smith SB, et al. Determination of nicotine content and delivery in disposable electronic cigarettes available in the United States by gas chromatography-mass spectrometry. NICTOB 2016:18:700-7.

16 Trtchounian A, Williams M, Talbot P. Conventional and electronic cigarettes (e-cigarettes) have different smoking characteristics. Nicotine Tobacco Research 2010;12:905-12.

17 Peleggi G. Prot. 0006615: Determining the rate of excise duty on products hby inhalation without burning consisting of liquid, containing or not containing nicotine, than those allowed on the market as products pursuant to Legislative Decree 24 April 2006, n. 21, as amended. Italian customs and Monopolies Agency, 2015.

$18 \mathrm{Ng} \mathrm{M}$, Freeman MK, Fleming TD, et al. Smoking prevalence and cigarette consumption in 187 countries, 1980-2012. JAMA 2014:311:183-92.

19 Liber AC, Drope JM, Stoklosa M. Combustible cigarettes cost less to use than ecigarettes: global evidence and Tax policy implications. Tob Control 2017;26:158-63.

20 Chaloupka FJ, Sweanor D, Warner KE. Differential Taxes for Differential Risks--Toward Reduced Harm from Nicotine-Yielding Products. N Engl J Med 2015:373:594-7.

21 Partos TR, Gilmore AB, Hitchman SC, et al. Availability and use of cheap tobacco in the United Kingdom 2002-2014: findings from the International tobacco control project. Nicotine Tob Res 2018;20:714-24. 